\title{
The Changing Face of Chronic Illness
}

Management in Primary Care: A Qualitative Study of Underlying Influences and Unintended Outcomes

\author{
Linda M. Hunt, $P b D^{1}$ \\ Meta Kreiner, MSc ${ }^{1}$ \\ Howard Brody, MD, $P b D^{2}$ \\ 'Department of Anthropology, Michigan \\ State University, East Lansing, Michigan \\ ${ }^{2}$ Institute for the Medical Humanities \& \\ Department of Family Medicine, University \\ of Texas Medical Branch, Galveston, Texas
}

Conflicts of interest: authors report none

\section{CORRESPONDING AUTHOR}

Linda M. Hunt, PhD

Department of Anthropology

354 Baker Hall

Michigan State University

East Lansing, MI 48824

huntli@msu.edu

\begin{abstract}
PURPOSE Recently, there has been dramatic increase in the diagnosis and pharmaceutical management of common chronic illnesses. Using qualitative data collected in primary care clinics, we assessed how these trends play out in clinical care.

METHODS This qualitative study focused on management of type 2 diabetes and hypertension in 44 primary care clinics in Michigan and was based on interviews with 58 clinicians and 70 of their patients, and observations of 107 clinical consultations. We assessed clinicians' treatment strategies and discussions of factors influencing treatment decisions, and patients' understandings and experiences in managing these illnesses.
\end{abstract}

RESULTS Clinicians focused on helping patients achieve test results recommended by national guidelines, and most reported combining 2 or more medications per condition to reach targets. Medication selection and management was the central focus of the consultations we observed. Polypharmacy was common among patients, with more than one-half taking 5 or more medications. Patient interviews indicated that heavy reliance on pharmaceuticals presents challenges to patient well-being, including financial costs and experiences of adverse health effects.

CONCLUSIONS Factors promoting heavy use of pharmaceuticals include lower diagnostic and treatment thresholds, clinician-auditing and reward systems, and the prescribing cascade, whereby more medications are prescribed to control the effects of already-prescribed medications. We present a conceptual model, the inverse benefit law, to provide insight into the impact of pharmaceutical marketing efforts on the observed trends. We make recommendations about limiting the influence of the pharmaceutical industry on clinical practice, toward improving the well-being of patients with chronic illness.

Ann Fam Med 2012;10:452-460. doi:10.1370/afm.1380.

\section{INTRODUCTION}

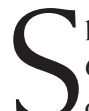
pending on prescription drugs in the United States has risen nearly 6-fold since $1990,{ }^{1}$ reflecting substantial increases in treatment of chronic conditions and subsequent polypharmacy. As many as $45 \%$ of Americans have at least 1 diagnosed chronic condition, ${ }^{2}$ and $60 \%$ of the most prescribed medications were for hypertension, high cholesterol levels, and diabetes. ${ }^{3}$ The Centers for Disease Control and Prevention estimates that $11 \%$ of the US population and $40 \%$ of people older than age 60 take 5 medications or more. ${ }^{4}$ Although some studies have documented health benefits with multiple medications, ${ }^{5}$ adverse drug reactions reported by the Food and Drug Administration tripled between 1995 and 2005, and research finds these reactions are the fourth leading cause of death in the United States. ${ }^{6}$ 
In this article, we review several factors underlying these developments and then consider how they play out in chronic illness management in primary care, using data from a qualitative study. Finally, we present a conceptual model to help explain these phenomena and their links to pharmaceutical industry marketing.

\section{FACTORS AFFECTING DIAGNOSIS AND TREATMENT}

What might explain the dramatic rise in the diagnosis and treatment of chronic illnesses? Increases in risk factors such as obesity no doubt affect these trends, but more proximate factors should also be considered.

One important factor is a pronounced lowering of diagnostic thresholds for common chronic conditions, notably diabetes and hypertension. Additionally, diagnostic thresholds for hypertension and elevated cholesterol are lower still for people with diabetes, and revised guidelines encourage treatment of predisease conditions, such as prehypertension and prediabetes. ${ }^{7-10}$ As a result, millions of people previously defined as healthy now are classified as needing treatment. ${ }^{11}$

Table 1 outlines some of these shifts in diagnostic standards and estimates the increase in numbers of cases diagnosed after these changes.

The speed and degree to which these changes affect clinical care are amplified by growth of programs that measure and reward physician performance. Clinicians are increasingly monitored to ensure patients' test numbers remain below given thresholds. ${ }^{6,13-15}$ Standard quality measures, such as the Healthcare Effectiveness Data and Information Set (HEDIS), ${ }^{16}$ which are annually released by the National Committee for Quality Assurance (NCQA), quickly incorporate lower thresholds set by guidelines committees. This practice is especially influential on physicians' decision making when combined with pay-for-performance incentive programs. Many insurance companies assess individual clinicians on the basis of whether their patients meet these standards, often paying substantial bonuses ${ }^{17}$ that encourage clinicians to respond to marginal test results with aggressive use of pharmaceuticals.

Additionally, prescription drugs often accumulate in what has been called a prescribing cascade, ${ }^{6,18}$ whereby a prescribed drug produces symptoms for which more drugs are prescribed, resulting in polypharmacy and further increasing the risk of adverse drug reactions. The prescribing cascade may be further sustained by clini- cians failing to recognize that the drug they prescribed caused the new symptoms, even when the symptoms are well known to be associated with that drug. ${ }^{19}$

Lower diagnostic criteria, greater use of quality measures and incentives, and the prescribing cascade all contribute to increased diagnosis of chronic illness and associated polypharmacy. To better understand how these factors operate in primary care, we turn to our study of a group of primary care clinicians and their patients.

\section{METHODS}

Two authors (L.M.H. and M.K.) studied primary care clinicians and their patients over a 2-year period (20092010), focusing on the management of 2 common chronic conditions: type 2 diabetes and hypertension. We set out to examine concepts of racial differences in chronic illness management. As anthropologists, our preconceptions led us to focus on the sociocultural aspects of clinical interactions and communication, and we were less concerned with the specific content of treatment approaches. As analysis proceeded, however, the prominence of prescription medications was so pronounced that we were prompted to examine that theme more closely.

We conducted interviews with a purposive sample of 58 clinicians from 44 primary care clinics in Michigan, including various types of practices, both public and private. The clinician sample included physicians, nurse practitioners, and physician assistants who were active in primary care, and excluded full-time academics and administrators. Recruitment strategies included tapping our personal networks, a university preceptor
Table 1. Criteria for Diagnosing Diabetes and Hypertension: Temporal Trends in Cutoffs for Starting Treatment ${ }^{9,11}$

\begin{tabular}{lccccc}
\hline Condition and Cutoff & 1992 & 1993 & 1998 & $\mathbf{2 0 0 3}$ & $\begin{array}{c}\text { Increase in } \\
\text { Diagnosed } \\
\text { Cases }\end{array}$ \\
\hline $\begin{array}{l}\text { Diabetes: fasting plasma } \\
\text { glucose, mg/dL }\end{array}$ & & & & & \\
$\quad \begin{array}{l}\text { Diabetes } \\
\text { Prediabetes }\end{array}$ & 140 & - & 126 & - & 10.3 million $^{\text {a }}$ \\
$\begin{array}{l}\text { Hypertension: blood } \\
\text { pressure, mm Hg }\end{array}$ & None & - & 110 & 100 & - \\
$\begin{array}{l}\text { In nondiabetic patients } \\
\text { In diabetic patients }\end{array}$ & $160 / 95$ & $140 / 90$ & - & - & 22.0 million $^{b}$ \\
Prehypertension & - & - & - & $130 / 80$ & - \\
\hline
\end{tabular}

aifference in the number of diagnosed cases of diabetes reported by the Centers for Disease Control and Prevention for 1997 and for 2009. ${ }^{39}$

bDifference in number of diagnosed cases of hypertension reported by the Centers for Disease Control and Prevention for 1991 and 2008. ${ }^{40,41}$ Because these numbers were reported as a percentage of the population aged older than 20 years (25\% in 1991 and 30\% in 2008), we used the US census reports of adult population size ${ }^{12}$ to convert to millions of people for this table. 
program, and a statewide physicians' research consortium, as well as snowball sampling. We attempted to contact 135 clinicians and interviewed 58; we were unable to reach 25 and determined that 22 did not fit recruitment criteria, and 30 declined to participate.

We observed 107 clinical consultations with 12 clinicians in 6 clinics. In the course of these observations, we recruited a purposive sample of 70 patients being treated for diabetes, hypertension, or both. We interviewed 4 to 7 patients for each of the 12 clinicians we observed. Of the 83 patients invited to be interviewed, 6 did not meet inclusion criteria, 4 could not be scheduled for interviews, and 3 declined.

We developed, piloted, and revised 2 sets of standardized open-ended unstructured questions followed by focused probes, with advice from a cross-disciplinary expert panel. Clinician interviews explored concepts and strategies for managing type 2 diabetes and hypertension. Patient interviews focused on understanding causes, course, and consequences of these diseases, and patients' treatment experiences.

Interviews averaged about 1 hour and were tape recorded and transcribed, yielding approximately 28 pages per interview. All study participants gave informed consent, following institutional review board approved protocols. To ensure anonymity, we have changed all names and personal details in this article.

Interview and observational data were coded into SPSS (SPSS Inc) ${ }^{20}$ and NVivo9 (QSR International Pty Ltd ${ }^{21}$ databases by a group of anthropology graduate assistants. As analysis proceeded, increasingly in-depth coding categories were generated, based on emerging thematic patterns. ${ }^{22}$ To ensure coding consistency, several research team members reviewed each case, and anomalies or discrepancies were resolved through consensus.

\section{RESULTS}

Tables 2 and 3 present demographic characteristics of the clinicians and patients interviewed, respectively. 2009-2010
We intentionally overrepresented low-income clinics and minority patients in our sample because we were especially interested in care for these populations.

\section{Polypharmacy}

The majority of patients $(89 \%, 62$ of 70$)$ reported taking multiple medications, averaging 4.8 prescriptions, with more than one-half $(51 \%, 36$ of 70$)$ taking 5 or morethe threshold commonly used to define polypharmacy. ${ }^{5,23}$ How readily prescriptions can accumulate is illustrated by the following case example.

\section{Table 2. Selected Characteristics of 58 Clinicians Interviewed, 2009-2010}

\begin{tabular}{lllc}
\hline Characteristic & No. (\%) & Characteristic & No. (\%) \\
\hline Sex & $26(45)$ & Degree \\
Male & $32(55)$ & Doctor of medicine & $34(59)$ \\
Female & & Doctor of osteopathy & $17(29)$ \\
Race/ethnicity & $37(63)$ & Physician assistant & $2(3)$ \\
Non-Hispanic white & $10(17)$ & Nurse practitioner & $5(9)$ \\
African American & $2(3)$ & Type of clinic & \\
Native American & $2(3)$ & University & $3(5)$ \\
Pacific Islander & $5(9)$ & Hospital/health system & $21(36)$ \\
Asian & $2(3)$ & Physician owned & $21(36)$ \\
Hispanic & FQHC & $8(14)$ \\
Age-group, $y^{\text {a }}$ & $12(21)$ & Other & $5(9)$ \\
$24-34$ & $19(33)$ & Location of clinic & $40(69)$ \\
$35-44$ & $16(27)$ & Urban & $7(12)$ \\
$45-55$ & $11(19)$ & Rural & $11(19)$ \\
$>55$ & Suburban & \\
\hline FQHC = Federally Qualified Health (enter. & & \\
age range: 27 to 77 years; median: 43 years. & & \\
\hline
\end{tabular}

Table 3. Selected Characteristics of 70 Patients Interviewed,

\begin{tabular}{lclc}
\hline Characteristic & No. (\%) & Characteristic & No. (\%) \\
\hline Sex & $33(47)$ & Diagnosis \\
Male & $37(53)$ & Diabetes only & $15(21)$ \\
Female & & Hypertension only & $14(20)$ \\
Race/ethnicity & Both diabetes and hypertension & $41(59)$ \\
Non-Hispanic white & $27(38)$ & Interview language & \\
African American & $21(30)$ & English & $53(76)$ \\
Native American & $3(4)$ & Spanish & $17(24)$ \\
Hispanic & $19(27)$ & Income ranges reported & $21(30)$ \\
Age-group, ya & & $<\$ 10,000$ & $16(23)$ \\
$24-34$ & $2(3)$ & $\$ 11,000-\$ 20,000$ & $15(21)$ \\
$35-44$ & $9(13)$ & $\$ 21,000-\$ 50,000$ & $4(6)$ \\
$45-54$ & $17(24)$ & $\$ 51,000-\$ 70,000$ & $4(6)$ \\
$55-65$ & $20(29)$ & $\$ 71,000-\$ 90,000$ & $4(6)$ \\
$>65$ & $22(31)$ & $>\$ 90,000$ & $6(9)$ \\
& & No answer & \\
\hline Age range: 32 to 85 years; median: 58 years. & & \\
\hline
\end{tabular}


Leroy, a 61-year-old African American man, is a laid-off forklift operator with no health insurance, living on less than $\$ 10,000$ a year in unemployment benefits. Ten years ago, he began taking hypertension medication after a heart attack. Two years ago, he received a diabetes diagnosis, for which he takes metformin. Since starting the hypertension and diabetes medications, he has developed severe indigestion and breathing problems, for which he has been prescribed additional medications. He is currently taking 3 medications for hypertension, 2 for diabetes, 2 for high cholesterol levels, 1 for acid reflux, and daily doses of aspirin and ibuprofen, and uses an inhaler for chronic bronchitis (chronic obstructive pulmonary disease), for a grand total of 11 medications.

We noted a common scenario: patients began medications after having moderately elevated test results (often at levels considered normal just a few years ago), developed additional symptoms, were found to have values falling outside reference ranges on other tests, and were prescribed more drugs. They were expected to continue these medications permanently: their target laboratory levels could be achieved only through continued use of these drugs.

\section{Emphasis on Medications}

Not surprisingly, given the number of medications patients were taking, the clinical consultations we observed focused heavily on choosing and adjusting medications, to the near exclusion of other considerations, such as diet and lifestyle. Below is a consultation typical of those we observed.

Janice, a neatly dressed 35-year-old African American woman, visits her physician for a checkup. The physician comes in the room, reading from her chart: "On your last visit you had an $\mathrm{A}_{1 \mathrm{c}}$ of $8.1[\%]$, and a fasting glucose of 128 $[\mathrm{mg} / \mathrm{dL}]$. You're on Lantus insulin, 20 units in the morning." He then looks up at her for the first time, and says, "So, how have you been doing?" She replies: "My sugars have been pretty good - the highest I've had is $137[\mathrm{mg} / \mathrm{dL}]^{\prime \prime} \ldots$ The doctor says: "That's okay—we're not too far off." ... He asks her what medications she is taking, and she lists 6 prescriptions: 4 for diabetes, 1 for asthma, and 1 for gastritis. "What was your lowest reading?" She answers, "67 [mg/dL]." He asks if she felt woozy or faint, and she says she did not. "That's good-it shows your body is getting used to lower glucose levels." They speak very briefly about her diet and exercise, he refers her for another test, and he tells her to come back for another checkup in 3 months.

The abundance of pharmaceutical marketing efforts to which these clinicians are exposed may contribute to such heavy emphasis on medications. Nearly threequarters of clinicians $(72 \%, 38$ of the 53 who discussed this topic) reported regular contact with pharmaceutical representatives, who provide drug information, free lunches, and free samples. Many $(62 \%, 33$ of 53$)$ saw more than 10 representatives weekly. While asserting they take drug representative information with a grain of salt, most $(77 \%, 41$ of 53$)$ found the information useful, as this physician assistant's comments illustrate:

A lot of times they will bring in updates on treatment recommendations.... They're slanting it towards their particular product - but it does sometimes give me some new information on the options for certain conditions.

\section{Guidelines}

The majority of the clinicians $(67 \%, 39$ of 58$)$ mentioned that the diagnostic criteria set out in clinical guidelines were important to their decision making. They clearly believed the guidelines are based on careful review of scientific evidence. When referring to specific target numbers, clinicians often used phrases such as "the literature tells us" or "research has found."

Only a handful of clinicians $(7 \%, 4$ of 58$)$ questioned the clinical soundness of using medications to achieve tight control, as called for by the guidelines. The vast majority expressed no reservations about the appropriateness of the goal numbers for diabetes and hypertension, or about the strategic use of medications to reach those targets. For example, consider this physician's comments about hypertension management:

We're looking for numbers below 140 over 90 [mm Hg]— and for less than 130 over $80[\mathrm{~mm} \mathrm{Hg}]$ for our diabetic patients.... Our first-line medications are typically a Dyazide, a Norvasc, or Accupril. Then usually we'll start trying combinations. Some of them may be on all 3. Some of them are on a lot more.

All said they usually combine at least 2 medications for either hypertension or diabetes, and nearly one-half $(43 \%, 25$ of 58$)$ regularly combine 3 or more drugs for these conditions. Furthermore, once a patient has a diabetes diagnosis, the goal numbers for hypertension and cholesterol are lower, so additional medications will be prescribed, quickly multiplying prescriptions. A quote from a family practice physician illustrates this phenomenon:

I tell most new diabetics that the sad news is that they're going to be on 5 meds.... That's just what's going to happen because their cholesterol parameters are lower [and] their blood pressure parameters are lower.... It's usually a pretty frank talk: "You have a deadly disease and it's going to kill you. How long you have it is up to you." (Laughs)

\section{Pay for Performance}

Pay-for-performance programs may further contribute to the prevalence of polypharmacy in these clinics. In both interviews and observations, clinicians were clearly aware that various institutions-insurance com- 
panies, employers, and others-were grading their performance. Several $(17 \%, 10$ of 58) frankly stated that this motivated them to reach target numbers. As one family physician said:

I was being a little bit lackadaisical with the $A_{1 c}$ goal as $7.0[\%]$ or less. I wouldn't really like to admit it, but the insurance companies making a financial carrot is probably one impetus for really cracking down on my diabetics to get them $7.0[\%]$ or less. $7.1[\%]$ don't cut it... anymore. It has to be $7.0[\%]$ or less.

\section{Multiplying Prescriptions}

A number of cases in our study illustrate the prescribing cascade. ${ }^{6,18}$ Patients on average were taking 4.8 prescriptions, with 3.3 being for hypertension, diabetes, high cholesterol, or some combination thereof. Nearly two-thirds of the patients $(60 \%, 42$ of 70$)$ were taking medications for other conditions, but it was difficult to parse which were for drug adverse effects. Still, most of those patients $(57 \%, 24$ of 42$)$ were taking additional medications for respiratory or gastric symptoms-well-known adverse effects of hypertension and diabetes medications.

Although more than half of clinicians $(55 \%, 32$ of 58) said they consider drug adverse effects in selecting medications, few expressed concern about medications causing negative health outcomes. They would simply comment matter-of-factly, "You've got to watch their kidneys with this one," or "I have to check their liver enzymes every now and then."

A number $(24 \%, 14$ of 58$)$ discussed the challenge of managing multiple medications, pointing out adverse effects of common medications that may worsen other conditions, requiring even more drugs, for example, $\beta$-blockers aggravating asthma symptoms, or antipsychotics elevating blood sugar. When discussing these complicated issues, only 1 clinician mentioned prescribing fewer drugs; all the rest focused on reaching goal numbers by either adding or changing medications.

\section{Patient Well-Being}

Although the clinicians in this study were clearly attempting to promote the well-being of their patients by combining drugs to reach optimal test numbers, the experiences reported by patients raise some concerns. Below is an illustration of how heavy reliance on pharmaceuticals can affect patients.

Sherie, a 54-year-old African American woman, is a recently unemployed cosmetologist who lost her health insurance several years ago. She has been taking hydrochlorothiazide and a $\beta$-blocker for hypertension for 13 years. Two years ago, she started taking metformin and glipizide after a random glucose reading of $130 \mathrm{mg} / \mathrm{dL}$, as a preventive measure, because of a strong family history of diabetes. After her diabetes diagnosis, her doctor used a lower diagnostic threshold for hypertension and for high cholesterol, and she was prescribed a third antihypertensive and a statin. Sherie is currently taking 8 prescription medications: 3 for hypertension, 2 for diabetes, 1 for high cholesterol levels, and 2 for depression. She has been able to get some of her medications through a county health program that offers generic medications for a $\$ 6$ copay. But, she explains, even that reduced amount is difficult for her: "I used to take my blood pressure pills every other day because every time I turned around I was buying more. And $\$ 6$ seems like it's not a lot, but it is when you ain't got it." She has recently started receiving 3 medications (Norvasc, Lipitor, and Zoloft) through the Pfizer patient assistance program, but she continues to struggle and is now coping with serious adverse effects. Her diabetes medications cause diarrhea and bouts of hypoglycemia, which interferes with her ability to leave her home because she must eat and go to the bathroom so frequently. She also had 5 visits to the emergency department in 1 month for excruciating headaches, before they were determined to be an adverse effect of the additional hypertension medication she had been prescribed after her diabetes diagnosis. She was able to change hypertension medication with the help of the Pfizer program. At her most recent appointment, her physician happily told her: "Your blood pressure is $130 / 78[\mathrm{~mm} \mathrm{Hg}]$, your $A_{1 c}$ is $7.0[\%]$, and your cholesterol was normal. Very good!"

On the basis of current standards, the clinician classified this patient as healthy, a success story; however, this classification does not address the broader question of her well-being. Getting test numbers into the stipulated range jeopardized her employment and led to repeated hospitalizations and serious financial burden.

Our patient interviews indicated that this situation is far from unique. The financial cost of multiple prescriptions has an important negative impact on many patients. Nearly one-half $(49 \%, 34$ of 70$)$ said the price of medications was a challenge. Clinicians did what they could to help control medication costs for patients, such as considering insurance in selecting medications, prescribing generics, giving samples, or helping patients participate in patient assistance programs. Although patients appreciated these efforts, the cost of drugs remained a major concern. The experiences of Karen, an unemployed, 45-year-old white woman with no insurance, highlight these issues. She described a serious hypoglycemic reaction to a lowcost insulin, for which she was hospitalized:

I had gotten really, really sick, and it just wasn't working at all. I went to [my doctor] and I was bawling and I told him: "I'm dying. I'm going to die, this is not working. I don't know what I'm going to do. I don't want to die." He hugged me and he told me that he would hook me up with samples of the Lantus.... And I was doing really well on that... I've applied for the company to send me the medicine for free 
because the insurance won't cover it...That will work for a year, and then I guess, I'll be begging [my doctor] to get samples through his office again.

Medication adverse effects are another serious challenge to patients' well-being. Two-thirds of the patients $(67 \%, 47$ of 70$)$ reported experiencing symptoms they attributed to their diabetes medications, hypertension medications, or both. This value may be an underestimation of the adverse effects of these drugs: several patients with diabetes $(35 \%, 19$ of 55$)$ attributed hypoglycemic symptoms to their disease rather than the diabetes medications, and one-half being treated for hypertension $(52 \%, 29$ of 56) blamed headache, dizziness, anxiety attacks, and other symptoms on their hypertension itself rather than the medications. Several patients $(13 \%, 9$ of 70$)$ had been hospitalized because of such symptoms, resulting in a medication change.

Although clinicians were aware that many patients struggle with the cost of drugs and with serious adverse effects, these were clearly secondary concerns from the clinicians' perspective. One physician succinctly expressed a sense of resignation about the inevitability of this trade-off in these words:

I've got patients on 4 different medications and their blood pressure is still uncontrolled. We try sending them to the cardiologists, and they say, "Just keep adding stuff because there's really nothing we can do about this."...Some people whose blood pressure that we do get normal again, they don't function very well at all. I'm not sure why.

\section{DISCUSSION}

Our study included a relatively small convenience sample of clinicians, so we can draw only tentative conclusions. Before our findings can be generalized to a broader population, they would need to be further examined in a representative sample. Still, the issues raised by this analysis are compelling and require careful consideration.

Through strategic use of an arsenal of pharmaceuticals, the clinicians in this study worked diligently to help their patients attain target blood pressure and glucose levels. We identified a variety of factors contributing to this pattern: lower diagnostic and treatment thresholds, clinician-auditing and reward systems, and the prescribing cascade effect. We also identified challenges to patient well-being resulting from heavy reliance on pharmaceuticals, especially financial costs and adverse drug effects. Although these costs are real and immediate, the potential benefit of attaining target numbers is abstract: lowering the risk of developing future disease. Why might clinicians be so accepting of these uncertain trade-offs?
One hypothesis is that clinicians are simply applying the best available scientific evidence to patient care; however, research regarding the value of these goal levels is far from straightforward. Evidence is accumulating that tight control may not in fact improve patient outcomes, and that harm to patients may actually increase with aggressive management of blood glucose and blood pressure. ${ }^{24-29}$ An alternative hypothesis is that our data reflect some degree of commercial influence over physician prescribing practices. A conceptual model, the inverse benefit law, proposed by Brody and Light, ${ }^{13}$ suggests how this might occur. Intended as a conceptual heuristic rather than a mathematically precise model, this law holds that the benefitto-harm ratio of a medication varies inversely with how aggressively the drug is marketed by industry. Pharmaceutical marketing prompts physicians to prescribe more drugs to more patients, with less and less chance of deriving long-term benefit, while exposing that nowmuch-larger drug-taking population to increased risk of adverse drug reactions. ${ }^{30}$

Critics have documented many deleterious health effects resulting from pharmaceutical industry marketing strategies. ${ }^{6,17,31-35}$ Applbaum ${ }^{36,37}$ argues that drug firms' marketing efforts focus on controlling entire drug "channels," the complex routes that drugs follow from manufacture to ingestion by patients. The treatment of diabetes and hypertension are areas where the industry may have effectively captured much of the channel. The very way practitioners think about these conditions promotes drug sales, by prioritizing abstract hoped-for patient benefits, while downplaying increased risks. ${ }^{14,17,38} \mathrm{We}$ found numerous instances of physicians acting in ways that the inverse benefit law would predict.

Lower diagnostic thresholds have resulted in large increases in the number of candidates for treatment, with an estimated 10 million additional people being treated for diabetes ${ }^{39}$ and 22 million for hypertension. ${ }^{40,41}$ These increases have 2 major implications for patient health. First, because these new cases have much less severe disease, their likelihood of benefitting is low (ie, the number needed to treat is high), but everyone has a roughly equal chance of experiencing adverse reactions, so the total burden of adverse reactions increases considerably. Second, the new cases have test values closer to normal when they begin treatment, so their risk for iatrogenic hypoglycemia or hypotension is higher than that in patients with more severe illness. Figure 1 presents a schematic representation of these relationships for the case of type 2 diabetes, illustrating the inverse association between potential benefit and potential harm as diagnostic thresholds decrease, increasing the number of people 


\section{Figure 1. Schematic representation of potential benefit and harm when the diagnostic threshold for type 2 diabetes is moved lower, increasing the number of people taking medications.}

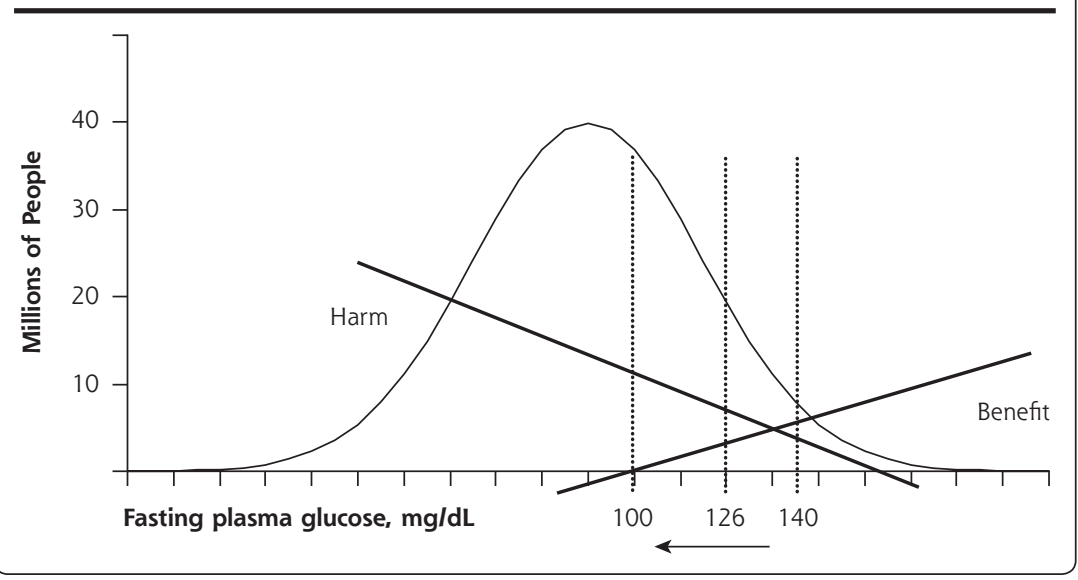

must assume that these marketing efforts have at least some influence on prescribing practices.

The value of programs offering low-cost or free medications may seem obvious, but on closer examination, the inverse benefit law again seems to be at play. Although these programs get brand-name medications to lowincome patients, they may also divert physicians from equally effective, more affordable generics. Even more concerning, they effectively draw patients into a long-term market for drugs they cannot afford

As would any clinician, those interviewed for this study wanted

taking medications for these conditions (also see the discussion of Welch et $\mathrm{a}^{11}$ on the ratio of potential net harm to net benefit for a variety of conditions, when diagnostic criteria are changed).

How might the industry that so dramatically profits from lowered treatment thresholds be affecting their establishment and promotion? We can identify a number of potential mechanisms, but because these influences are intentionally obscured, our argument is speculative.

The pharmaceutical industry influence goes beyond marketing directly to physicians. The industry has frequently been shown to systematically generate and publish research findings that promote their drugs. ${ }^{31}$ ${ }^{35,42}$ The industry may also influence the establishment of clinical standards. It would be imprudent to claim that the industry dictates these standards; however, the committees and organizations setting the standards often have substantial pharmaceutical industry support and include many individuals with industry ties. ${ }^{14,43,44}$

As we saw, increasing use of grading and reward programs may amplify clinician interest in reaching goal numbers. Although such programs encourage clinicians to aggressively use pharmaceuticals to reach target numbers ${ }^{45-47}$ there is no consensus on whether they actually improve overall outcomes. ${ }^{48}$ Those who prescribe more judiciously, prioritizing patient benefit over marginal improvements in test values, may actually be penalized by this system.

An obvious industry influence is the impressive presence of the drug representatives in the practices included in our study. A recent national survey reported that $87 \%$ of physicians have regular contact with these marketing professionals. ${ }^{49}$ Given that the industry spends an estimated $\$ 53$ billion annually on marketing pharmaceuticals to US physicians, ${ }^{50}$ one to offer quality care, meet practice standards, and prevent serious downstream complications. But in adhering to authoritative medical guidelines, they are diagnosing and treating test levels closer to normal and prescribing more and more drugs, while unaware of the influence that the pharmaceutical industry may have had on establishing the standards and practices they follow. ${ }^{34,36,49}$

The influence of the pharmaceutical industry on the marketing of medications for these chronic illnesses appears very successful. Although quite beneficial for industry profits, the consequences may include worsening health and increased risks from medications for patients. ${ }^{6,13} \mathrm{~A}$ full discussion of what might be done to reverse these troublesome trends is beyond the scope of this article. At a minimum, we urge policies excluding individuals or organizations with financial conflicts of interest from involvement with guideline-writing panels. The presumption that mere disclosure resolves such conflicts must be rejected. ${ }^{51,52}$ Physicians should be discouraged from seeing drug representatives, through programs such as the Unbranded Doctor program of the National Physicians Alliance. ${ }^{53}$ Payfor-performance plans should be monitored closely for evidence of unintended negative effects on patients. Together, such policy changes may slow the disturbing trends our findings illustrate.

To read or post commentaries in response to this article, see it online at http://www.annfammed.org/content/10/5/452.

Key words: pharmaceutical marketing; physician incentive programs; chronic illness; polypharmacy; clinical practice guidelines; prescribing patterns, physician; drug therapy; diabetes mellitus; hypertension

Submitted April 14, 2011; submitted, revised, November 9, 2011; accepted December 1, 2011. 
Funding support: This research was supported by the National Institute of Health, National Center for Human Genome Research through grant HG004710-03.

Acknowledgments: We wish to thank the clinicians, clinical staff, and patients who participated in this study, whose kind cooperation made this research possible. Amanda Abramson, Kristan Ewell, Linda Gordon, Heather Howard, Lynette King, Isabel Montemayor, Fredy Rodriguez, and Kimme Rovin provided invaluable assistance with a variety of data collection, analysis, and literature review tasks. We also wish to thank 3 anonymous reviewers for their very helpful comments.

\section{References}

1. Kaiser Family Foundation. Prescription Drug Trends. May 2010. http://www.kff.org/rxdrugs/upload/3057-08.pdf. Accessed Feb 4, 2011.

2. Cory S, Ussery-Hall A, Griffin-Blake S, et al; Centers for Disease Control and Prevention. Prevalence of selected risk behaviors and chronic diseases and conditions-Steps communities, United States, 2006-2007. MMWR Surveill Summ. 2010;59(SS08):1-37.

3. Herper M. America's most popular drugs: a narcotic painkiller tops Forbes' list of the most prescribed medicines. Forbes. May 11 2010. http://www.forbes.com/2010/05/11/narcotic-painkiller-vicodinbusiness-healthcare-popular-drugs.html. Accessed Nov 15, 2010.

4. Gu Q, Dillon CF, Burt VL. Prescription drug use continues to increase: U.S. prescription drug data for 2007-2008. NCHS Data Brief. 2010;(42):1-8

5. Bushardt RL, Massey EB, Simpson TW, Ariail JC, Simpson KN. Polypharmacy: misleading, but manageable. Clin Interv Aging. 2008 3(2):383-389.

6. Light DW. Bearing the risks of prescription drugs. In: Light DW, ed. The Risks of Prescription Drugs. New York, NY: Columbia University Press; 2010:1-39.

7. American Diabetes Association. Standards of medical care in diabetes-2010. Diabetes Care. 2010;33(Suppl 1):S11-S61.

8. Chobanian AV, Bakris GL, Black HR, et al; Joint National Committee on Prevention, Detection, Evaluation, and Treatment of High Blood Pressure. National Heart, Lung, and Blood Institute; National High Blood Pressure Education Program Coordinating Committee. Seventh report of the Joint National Committee on Prevention, Detection, Evaluation, and Treatment of High Blood Pressure. Hypertension. 2003;42(6):1206-1252

9. Rosendorff C, Black HR, Cannon CP, et al; American Heart Association Council for High Blood Pressure Research; American Heart Association Council on Clinical Cardiology; American Heart Association Council on Epidemiology and Prevention. Treatment of hypertension in the prevention and management of ischemic heart disease: a scien tific statement from the American Heart Association Council for High Blood Pressure Research and the Councils on Clinical Cardiology and Epidemiology and Prevention. Circulation. 2007;115(21):2761-2788.

10. Woolf SH, Rothemich SF. New diabetes guidelines: a closer look at the evidence. Am Fam Physician. 1998;58(6):1287-1288, 1290.

11. Welch HG, Schwartz LM, Woloshin S. Overdiagnosed: Making People Sick in the Pursuit of Health. Boston, MA: Beacon Press; 2011:171-172.

12. US Census Bureau: Statistical Abstract of the United States 2011. Table 7: Resident Population by Sex and Age: 1980 to 2009. http://www.census.gov/compendia/statab/2011/tables/11s0007.pdf. Accessed Aug 15, 2011

13. Brody $\mathrm{H}$, Light DW. The inverse benefit law: how drug marketing undermines patient safety and public health. Am J Public Health. 2011;101(3):399-404

14. Greene JA. Prescribing by Numbers: Drugs and the Definition of Disease. Baltimore, MD: Johns Hopkins University Press; 2007.
15. Rockhill B. The privatization of risk. Am J Public Health. 2001; 91(3):365-368.

16. National Committee for Quality Assurance (NCQA), Feb 15, 2007. Expanded HEDIS Specifications For Physician Measurement Opened To Public Comment. http://www.ncqa.org/tabid/191/Default.aspx. Accessed Nov 15, 2010

17. Brody $\mathrm{H}$. The commercialization of medical decisions: physicians and patients at risk. In: Light DW, ed. The Risks of Prescription Drugs. New York, NY: Columbia University Press; 2010:70-91.

18. Rochon PA, Gurwitz JH. Optimising drug treatment for elderly people: the prescribing cascade. BMJ. 1997;315(7115):1096-1099.

19. Golomb BA, McGraw JJ, Evans MA, Dimsdale JE. Physician response to patient reports of adverse drug effects: implications for patienttargeted adverse effect surveillance. Drug Saf. 2007;30(8):669-675.

20. SPSS Inc. SPSS for Windows. Release 18. Chicago, IL: SPSS Inc; 2009.

21. QSR International Pty Ltd. NVivo qualitative data analysis software. Version 9. Cambridge, MA: QSR International Pty Ltd; 2010

22. Bernard HR. Research Methods in Anthropology. New York, NY: Alta Mira Press: 2006

23. Viktil KK, Blix HS, Moger TA, Reikvam A. Polypharmacy as commonly defined is an indicator of limited value in the assessment of drug-related problems. Br J Clin Pharmacol. 2007;63(2):187-195.

24. Gerstein HC, Miller ME, Genuth S, et al; ACCORD Study Group. Long-term effects of intensive glucose lowering on cardiovascular outcomes. N Engl J Med. 2011;364(9):818-828.

25. Pogach LM, Rajan M, Maney M, Tseng CL, Aron DC. Hidden complexities in assessment of glycemic outcomes: are quality rankings aligned with treatment? Diabetes Care. 2010;33(10):2133-2139.

26. Choe HM, Bernstein SJ, Standiford CJ, Hayward RA. New diabetes HEDIS blood pressure quality measure: potential for overtreatment. Am J Manag Care. 2010;16(1):19-24.

27. Cooper-DeHoff RM, Gong Y, Handberg EM, et al. Tight blood pressure control and cardiovascular outcomes among hypertensive patients with diabetes and coronary artery disease. JAMA. 2010; 304(1):61-68.

28. Zoungas S, Patel A, Chalmers J, et al; ADVANCE Collaborative Group. Severe hypoglycemia and risks of vascular events and death. N Engl J Med. 2010;363(15):1410-1418.

29. Currie CJ, Peters JR, Tynan A, et al. Survival as a function of $\mathrm{HbA}_{1 \mathrm{c}}$ in people with type 2 diabetes: a retrospective cohort study. Lancet. 2010;375(9713):481-489.

30. Mold JW, Hamm RM, McCarthy LH. The law of diminishing returns in clinical medicine: how much risk reduction is enough? J Am Board Fam Med. 2010;23(3):371-375

31. Kassirer JP. On the Take: How America's Complicity With Big Business Can Endanger Your Health. New York, NY: Oxford University Press: 2005

32. Abramson J. Overdo\$ed America: The Broken Promise of American Medicine. 1st ed. New York, NY: HarperCollins; 2004.

33. Avorn J. Powerful Medicines: The Benefits, Risks, and Costs of Prescription Drugs. 1st ed. New York, NY: Knopf; 2004.

34. Brody H. Hooked: Ethics, the Medical Profession, and the Pharmaceutical Industry. Lanham, MA: Rowman \& Littlefield; 2007.

35. Angell M. The Truth About the Drug Companies: How They Deceive Us and What to Do About It. 1st ed. New York, NY: Random House; 2004.

36. Applbaum K. Getting to yes: corporate power and the creation of a psychopharmaceutical blockbuster. Cult Med Psychiatry. 2009; 33(2):185-215.

37. Applbaum K. Shadow science: Zyprexa, Eli Lilly and the globalization of pharmaceutical damage control. Biosocieties. 2010;5:236-255. 
38. Light DW, ed. The Risks of Prescription Drugs. New York, NY: Columbia University Press; 2010.

39. Centers for Disease Control and Prevention. Diabetes Data $\varepsilon$ Trends. Dec 9, 2011. http://www.cdc.gov/diabetes/statistics/prev/ national/figpersons.htm. Accessed Aug 15, 2011.

40. Yoon SS, Ostchega $Y$, Louis T. Recent trends in the prevalence of high blood pressure and its treatment and control, 1999-2008. NCHS Data Brief. 2010;Oct(48):1-8.

41. Hajjar I, Kotchen TA. Trends in prevalence, awareness, treatment, and control of hypertension in the United States, 1988-2000. JAMA 2003;290(2):199-206.

42. Elliott C. White Coat, Black Hat: Adventures on the Dark Side of Medicine. Boston, MA: Beacon Press; 2010.

43. Oldani MJ. Assessing the 'relative value' of diabetic patients treated through an incentivized, corporate compliance model. Anthropol Med. 2010;17(2):215-228

44. Choudhry NK, Stelfox HT, Detsky AS. Relationships between authors of clinical practice guidelines and the pharmaceutical industry. JAMA. 2002;287(5):612-617.

45. Tanenbaum SJ. Pay for performance in Medicare: evidentiary irony and the politics of value. J Health Polit Policy Law. 2009;34(5):717-746.

46. Ohldin A, Mims A. The search for value in health care: a review of the National Committee for Quality Assurance efforts. J Natl Med Assoc. 2002;94(5):344-350.
47. Christianson JB, Leatherman S, Sutherland K. Lessons from evaluations of purchaser pay-for-performance programs: a review of the evidence. Med Care Res Rev. 2008;65(6 Suppl):5S-35S.

48. Serumaga B, Ross-Degnan D, Avery AJ, et al. Effect of pay for performance on the management and outcomes of hypertension in the United Kingdom: interrupted time series study. BMJ. 2011;342:d108.

49. Campbell EG, Rao SR, DesRoches CM, et al. Physician professionalism and changes in physician-industry relationships from 2004 to 2009. Arch Intern Med. 2010;170(20):1820-1826.

50. Gagnon MA, Lexchin J. The cost of pushing pills: a new estimate of pharmaceutical promotion expenditures in the United States. PLoS Med. 2008;5(1):e1.

51. Rodwin MA. Conflicts of Interest and the Future of Medicine in the United States, France, and Japan. Oxford, England: Oxford University Press; 2010.

52. Mendelson TB, Meltzer M, Campbell EG, Caplan AL, Kirkpatrick JN. Conflicts of interest in cardiovascular clinical practice guidelines. Arch Intern Med. 2011;171(6):577-584.

53. National Physicians Alliance. The Unbranded Doctor. http://npalliance.org/action/the-unbranded-doctor. Accessed Mar 17, 2011. 